\title{
Pd Nanoparticles Stabilized on the Cross-Linked Melamine-Based SBA-15 as a Catalyst for the Mizoroki-Heck Reaction
}

\author{
Ayat Nuri ${ }^{1,2} \cdot$ Abolfazl Bezaatpour $^{1} \cdot$ Mandana Amiri $^{1} \cdot$ Nemanja Vucetic $^{2} \cdot$ Jyri-Pekka Mikkola $^{2,3} \cdot$ Dmitry Yu. Murzin $^{2}$
}

Received: 31 March 2021 / Accepted: 29 May 2021 / Published online: 11 June 2021

(C) The Author(s) 2021

\begin{abstract}
Mesoporous SBA-15 silicate with a high surface area was prepared by a hydrothermal method, successively modified by organic melamine ligands and then used for deposition of Pd nanoparticles onto it. The synthesized materials were characterized with infrared spectroscopy (FT-IR), thermogravimetric analysis (TGA), nitrogen physisorption, scanning electron microscopy (SEM) coupled with energy dispersive X-ray analysis (EDX), transmission electron microscopy (TEM), nuclear magnetic resonance (NMR) and inductively coupled plasma (ICP-OES). The catalyst was effectively used in the MizorokiHeck coupling reaction of various reactants in the presence of an organic base giving the desired products in a short reaction time and with small catalysts loadings. The reaction parameters such as the base type, amounts of catalyst, solvents, and the temperature were optimized. The catalyst was easily recovered and reused at least seven times without significant activity losses.
\end{abstract}

Dmitry Yu. Murzin

dmurzin@abo.fi

1 Department of Applied Chemistry, Faculty of Science,

University of Mohaghegh Ardabili, Ardabil, Iran

2 Johan Gadolin Process Chemistry Centre, Laboratory of Industrial Chemistry and Reaction Engineering, Åbo Akademi University, Biskopsgatan 8, 20500 Turku-Åbo, Finland

3 Technical Chemistry, Department of Chemistry, Chemical-Biological Center, Umeå University, 90187 Umeå, Sweden 


\section{Graphic Abstract}

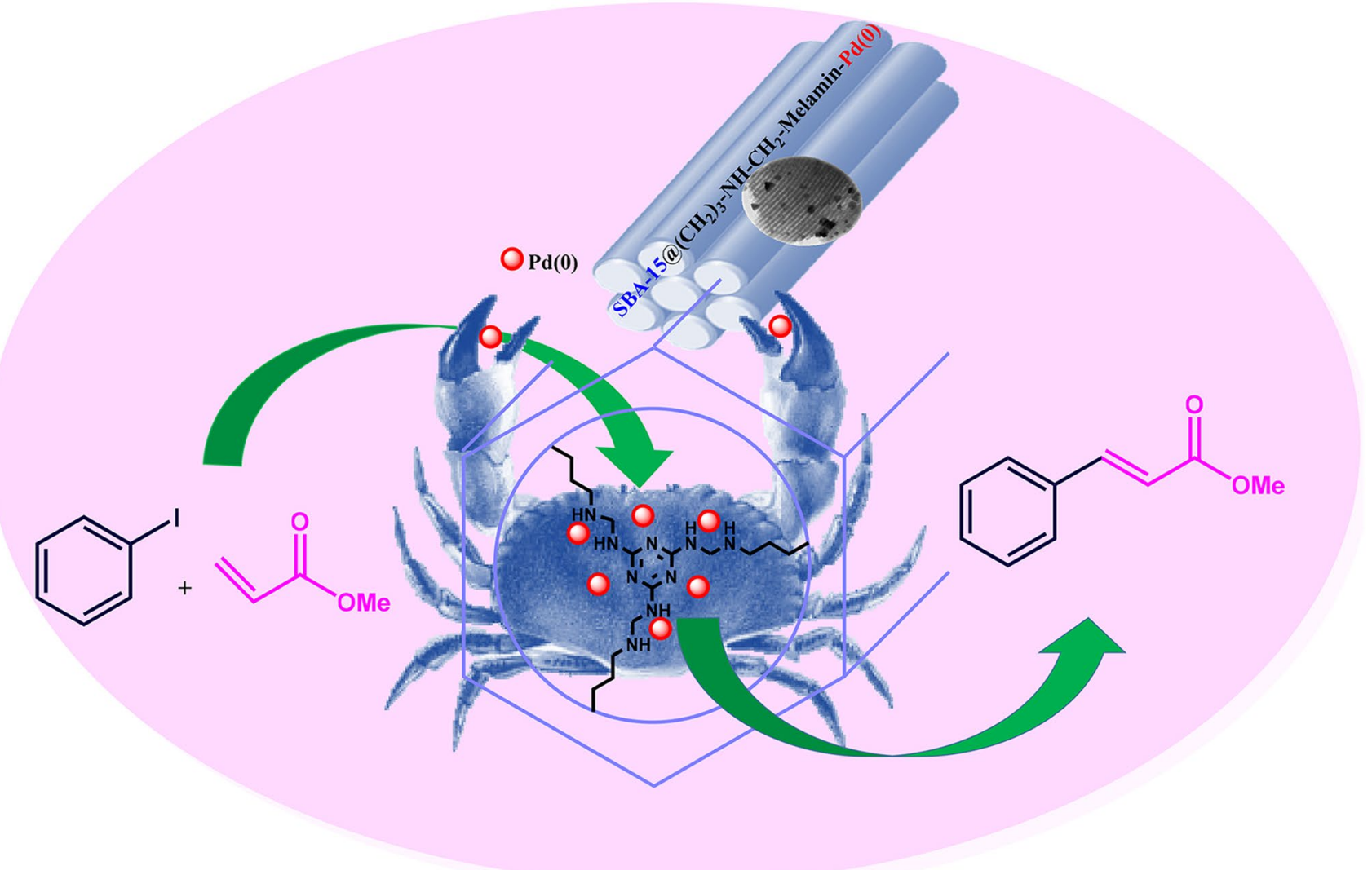

Keywords Mesoporous SBA-15 $\cdot$ Mizoroki-Heck reaction $\cdot$ Pd nanoparticles

\section{Introduction}

In the synthetic organic chemistry and production of fine chemicals $\mathrm{C}-\mathrm{C}$ cross-coupling reactions are highly ranked. In generally they present a robust way for $\mathrm{C}-\mathrm{C}$ bonds formation and production of the diverse molecules with high selectivity toward R-R' compounds. Among them the Mizoroki-Heck reaction is considered as one of the most important tools for coupling of aryl and vinyl halides or triflates with the molecules possessing $s p^{2} \mathrm{CH}$ bonds such as olefins and acrylates (Scheme 1) [1,2]. Its popularity is connected to its versatility toward many reactants and resistance to<smiles>[R]C=CCCO[R](=O)c1ccc(C=C[R])cc1</smiles>

Scheme 1 Scheme of the Mizoroki-Heck reaction different functional groups. In most of the cases the reaction is catalyzed by palladium, nonetheless other more abundant metals can be catalytically active under specific conditions making it much more environmental friendly alternative $[3,4]$. Different reagents cane be utilized in Mizoroki-Heck reactions from the less reactive bromo- and chloro-compounds on one side to non-activated alkenes on the other, thus becoming attractive for industrial productions [5]. Reaction can yield $\mathrm{E}$ and $\mathrm{Z}$ types of products, but usually the E product type is predominant [6-9]. It can be used for creating the bonds within the molecule (intra-molecular) or between different reactants (inter-molecularly). Initially the inter-molecular form of the reaction was extensively studied in the past, [10] while intra-molecular reaction was described more lately [11].

There was a long debate in the literature whether homogeneous or heterogeneous species are catalyzing the Mizoroki-Heck reaction. The most commonly agreed mechanism of this reaction comprises leaching of palladium from the catalyst surface, its participation in the catalytic cycle and re-deposition back after the reaction completion [12-15]. 
Such a mechanism requires a careful choice of the catalyst and the reactor. Evidently, in batch processes homogeneous palladium catalysts can be used, however, such type of catalysis comes along with an important issue of catalyst separation and reusability, whereas recovery of noble metals is very important in terms of costs and environment impact. On the other hand, easy recycling of heterogeneous catalysts is an important advantage, with a clear disadvantage related to insufficient selectivity and catalyst leaching. Development of an easily separable heterogeneous catalyst was in the focus of many research groups and brought versatile solutions [16-18]. For example, many efforts were put on designing a heterogenized ligand system capable of stabilizing Pd giving thereby a highly active and reusable catalyst [19]. Besides high activity, a goal is to achieve a maximum catalyst recovery level. This could be done by taking an advantage of magnetic features embedded into a palladium complex deposited on silica coatings [20].

Parallel with development of catalytically active components various types of supports were explored. Highly ordered mesoporous silica materials SBA- 15 have a potential to be utilized in many different applications, catalysis being one of the most important. The reasons for it are their properties, such as high surface areas $\left(700-1200 \mathrm{~m}^{2} \mathrm{~g}^{-1}\right)$, non-toxicity, chemical and physical inertness, abundance of silanol groups capable for functionalization, along with tunable physical properties such as the pore diameter and walls thickness. SBA-15 possesses hydrothermal stability due to thick and uniform silica walls (3.1 to $6.4 \mathrm{~nm}$ ) with a two-dimensional (2D) hexagonal (p6mm) meso-structure of the channels and a large pore size $(4.6-10.0 \mathrm{~nm})$. As a consequence, SBA-15 was considered as a material appropriate for simple functionalization and tuned selectivity in catalysis, as well as for deposition and release of pharmaceutically active compounds in drug delivery applications [21-24]. A typical example is design of palladium supported DHBP@ SBA-15 catalyst obtained by adding 2,2-dihydroxybenzopheneone ligand to amine functionalized mesoporous silica followed by metalation with $\mathrm{Pd}(\mathrm{II})$. This yielded a highly active catalyst in Mizoroki-Heck (arylation) and hydrogenation reactions without a significant loss of activity in several reaction cycles [25].

The current work discusses design and characterization of a new catalyst derived from melamine modified SBA15 loaded with Pd nanoparticles. The catalyst performance was optimized for the Mizoroki-Heck reaction of iodobenzene and methyl acrylate in which it displayed high activity and reusability. The scope was extended to different iodo-, bromo- and chloro-aromatic compounds.

\section{Experimental}

\subsection{Materials}

Pluronic P123, tetraethyl orthosilicate (TEOS), 3-aminopropyltriethoxysilane (APTS), melamine, paraformaldehyde, $\mathrm{PdCl}_{2}, \mathrm{NaBH}_{4}$, iodobenzene, ethyl acrylate and organic/ inorganic bases were obtained from Sigma Aldrich and used without further purification. Other chemicals were of analytical purity grade obtained from Alfa Aesar.

\subsubsection{Synthesis of SBA-15}

SBA-15 was synthesized according to the following procedure found in the literature [26]. In $30 \mathrm{~mL}$ of water $4.0 \mathrm{~g}$ of P123 was dissolved, followed by adding the mixture to $120 \mathrm{~mL}$ of $2 \mathrm{M} \mathrm{HCl}$ solution. After the solution became homogeneous, $9.0 \mathrm{~g}$ of tetraethyl orthosilicate was added, and the mixture was stirred for $8 \mathrm{~h}$ at $40{ }^{\circ} \mathrm{C}$. The uniform reaction mixture was transferred into a Teflon-lined stainless-steel autoclave and aged at $100{ }^{\circ} \mathrm{C}$ for $24 \mathrm{~h}$. After cooling down to the room temperature, the product was filtered, washed with water and $\mathrm{EtOH}$, then dried overnight at 100 ${ }^{\circ} \mathrm{C}$. The white solid was calcined at $560-600{ }^{\circ} \mathrm{C}$ for $6 \mathrm{~h}$ to remove the template.

\subsubsection{Synthesis of SBA-15/Pr-NH}

In order to functionalize mesoporous silica SBA-15 $1.00 \mathrm{~g}$ of this material reacted under reflux conditions with $1.5 \mathrm{ml}$ of 3 -aminopropyltrimethoxysilane $(6.5 \mathrm{mmol})$ in $50 \mathrm{ml}$ dry toluene under $\mathrm{N}_{2}$ for $24 \mathrm{~h}$. The product was filtered and washed three times with $40 \mathrm{~mL}$ diethylether and $40 \mathrm{~mL}$ toluene to remove unreacted reagents, followed by evaporation of the solvent giving a white powder $\left(\mathrm{SBA}-15 / \mathrm{Pr}-\mathrm{NH}_{2}\right)$ [27].

\subsubsection{Cross-Linked Melamine Functionalization of SBA-15}

To synthesize the cross-linked melamine functionalized SBA-15 in a 4-neck round bottom flask all amino-functionalized SBA-15 from the previous step together with melamine $(2.8 \mathrm{mmol}, 0.35 \mathrm{~g})$ and paraformaldehyde $(22.4 \mathrm{mmol}$, $0.68 \mathrm{~g}$ ) was added and sonicated in $20 \mathrm{ml}$ of DMF under nitrogen for $30 \mathrm{~min}$. After sonication, the reaction mixture was refluxed upon stirring for $24 \mathrm{~h}$ at $90^{\circ} \mathrm{C}$ under nitrogen atmosphere. The mixture was cooled to room temperature and then washed with DMF, distillated water and acetone. Finally, the solid cross-linked melamine functionalized SBA-15 was dried overnight at $60{ }^{\circ} \mathrm{C}$ [28]. 


\subsubsection{Preparation of SBA-15/Pr-NH-CH - -Melamine-Pd(0)}

To deposit the metal $1.00 \mathrm{~g}$ of synthesized SBA-15/Pr$\mathrm{NH}-\mathrm{CH}_{2}$-Melamine was first dispersed in $10 \mathrm{ml} \mathrm{EtOH}$ at room temperature. Into SBA-15 suspension $0.10 \mathrm{~g}$ of $\mathrm{PdCl}_{2}$ dissolved in $20 \mathrm{ml} \mathrm{EtOH}$ was added, followed by stirring for $24 \mathrm{~h}$ at room temperature. Limited solubility of palladium chloride in the solvent required several deposition steps until the metal precursor was completely deposited. Finally, the solid catalyst was separated by centrifugation and washed three times with $\mathrm{EtOH}$ and twice with dicholorometane to remove the unreacted reagents, then kept overnight at $70^{\circ} \mathrm{C}$. Subsequently, the solid product was reduced by $25 \mathrm{~mL}$ of $0.1 \mathrm{M}$ sodium borohydride aqueous solution to give a dark brown mixture, separated by centrifugation, washed with distilled water and EtOH [29]. Reduction with a chemical reducing agent -sodium borohydride is a well-established method for generating $\operatorname{Pd}(0)$ particles [30]. After drying a grey solid was obtained containing $6.0 \% \mathrm{wt}$ Pd according to ICP-OES.

\subsection{Characterization}

Modification of SBA-15 by organics was monitored by infrared spectroscopy (Mattson ATI Genesis FTIR Spectrometer). The specific surface area and the pore size were studied by $\mathrm{N}_{2}$ physisorption performed on Sorptometer 1900 (Carlo-Erba Instruments). The structure of SBA-15 derived material coupled with elemental analysis was investigated by scanning electron microscopy (Zeiss Leo-1530 Gemini) with a Thermo-NORAN vantage X-ray detector. Palladium nanoparticles size distributions and SBA-15 channels dimensions were investigated by transmission electron microscopy (TEM) performed on LEO 912 OMEGA (EFTEM) with acceleration voltage $120 \mathrm{kV}$ and LaB6 electron source. Thermogravimetric analysis (TGA) was conducted with a Linseis STA PT 1000 instrument using a scanning rate of $10{ }^{\circ} \mathrm{C} \mathrm{min}^{-1}$. The palladium content in solid samples was determined by inductively coupled plasma optical emission spectroscopy (ICP-OES), with Optima 4300 DV optical atomic emission spectrometer (Perkin Elmer). CP MAS ${ }^{13} \mathrm{C}$ NMR spectrum of the catalyst was made with a Bruker AVANCE-III HD $400 \mathrm{MHz}$ spectrometer. The sample was spun at $9 \mathrm{kHz}$ spin rate in a Bruker ${ }^{1} \mathrm{H}$ broadband double-resonance $4 \mathrm{~mm} \mathrm{CP}$ MAS probe with the proton $90^{\circ}$ high-power pulse of $2.9 \mu$ s and the contact time of $2 \mathrm{~ms}$. The recovery delay time was $2 \mathrm{~s}$ and 30,000 scans were accumulated.

Low-angle XRD in the $2 \theta$ range $0.7-10^{\circ}$ was conducted with Philips X-Pro (scanning rate $1^{\circ} \mathrm{min}^{-1}$ ) instrument operating at room temperature and equipped with an $\mathrm{X}$-ray radiation source using $\mathrm{Cu} \mathrm{K}_{\alpha}(\lambda=0.15406 \mathrm{~nm})$.
The reaction yield was followed by HP 6890 Series gas chromatograph (GC) equipped with the flame ionization detector and HP-5, 5\% phenyl methyl siloxane capillary column $(30.0 \mathrm{~m}, 320 \mu \mathrm{m}, 0.25 \mu \mathrm{m})$. The injection temperature was $280{ }^{\circ} \mathrm{C}$ while the gas flow rate was $9.5 \mathrm{ml} \mathrm{min}{ }^{-1}$. The aliquots were diluted and mixed with an internal standard solution of hexadecane.

\subsection{Mizoroki-Heck Coupling}

In general Mizoroki-Heck reaction was performed by using $1.0 \mathrm{mmol}$ of iodobenzene, $1.5 \mathrm{mmol}$ methyl acrylate, $1.5 \mathrm{mmol}$ triethylamine $\left(\mathrm{Et}_{3} \mathrm{~N}\right), 0.001 \mathrm{~g} \mathrm{SBA}-15 / \mathrm{Pr}-$ $\mathrm{NH}-\mathrm{CH}_{2}-\mathrm{Melamine}-\mathrm{Pd}(0)$ as a catalyst $(0.28 \mathrm{~mol} \% \mathrm{Pd}$ to aryl halide) and $1.0 \mathrm{ml}$ of dimethylformamide (DMF) as a solvent at $120^{\circ} \mathrm{C}$ for $15 \mathrm{~min}$. The reaction was carried out in glass vial tubes supplied with a magnetic stirrer and heated by an oil bath, while the reaction progress and the halide consumption was monitored by TLC. Upon completion, the aliquots were analyzed with GC and the catalyst was separated from the slurry by filtration. The reaction mixture was washed with diethyl ether and ethyl acetate. The organic phase was separated after evaporation of the solvent under reduced pressure and the pure product was obtained by the plate chromatography on silica.

\section{Results and Discussion}

\subsection{Catalyst Synthesis and Characterization}

SBA-15 was synthesized via the hydrothermal method from TEOS and pluronic P123 polymer. After calcination, SBA15 was functionalized by amine groups and modified by melamine and paraformaldehyde under sonication. After grafting the surface of SBA-15 by organic groups, $\mathrm{PdCl}_{2}$ was deposited on the surface and then reduced to $\operatorname{Pd}(0)$ by $\mathrm{NaBH}_{4}$ giving the final catalyst SBA-15/Pr-NH- $\mathrm{CH}_{2}-\mathrm{Mela}-$ mine- $\mathrm{Pd}(0)$ as illustrated in Scheme 2.

The FT-IR spectra for SBA-15, SBA-15/Pr- $\mathrm{NH}_{2}$, SBA15/Pr-NH- $\mathrm{CH}_{2}$-Melamine, SBA-15/Pr-NH-CH ${ }_{2}$-Melamine-Pd(0) are shown in Fig. 1a. The peaks at 467, 812 and $1088 \mathrm{~cm}^{-1}$ in all samples are related to $\mathrm{Si}-\mathrm{O}-\mathrm{Si}$ bonds in SBA-15. Vibrations of the silanol groups are present at $3420 \mathrm{~cm}^{-1}$. Vibrations corresponding to $\mathrm{NH}_{2}$ bending and hydrogen-bonding of water molecules on the surface overlap at 1610 to $1640 \mathrm{~cm}^{-1}$. Asymmetric and symmetric $\mathrm{C}-\mathrm{H}$ stretching of propyl chain are present at 2882 and $2936 \mathrm{~cm}^{-1}$. After functionalization of SBA-15/( $\left.\mathrm{CH}_{2}\right)_{3}-\mathrm{NH}_{2}$ with melamine, three new peaks were revealed at the 1361 , 1515 and $1572 \mathrm{~cm}^{-1}$ showing presence of melamine on the surface of SBA-15 [31]. The spent catalyst exhibited essentially the same vibrations as the fresh one (Fig. 1b). 


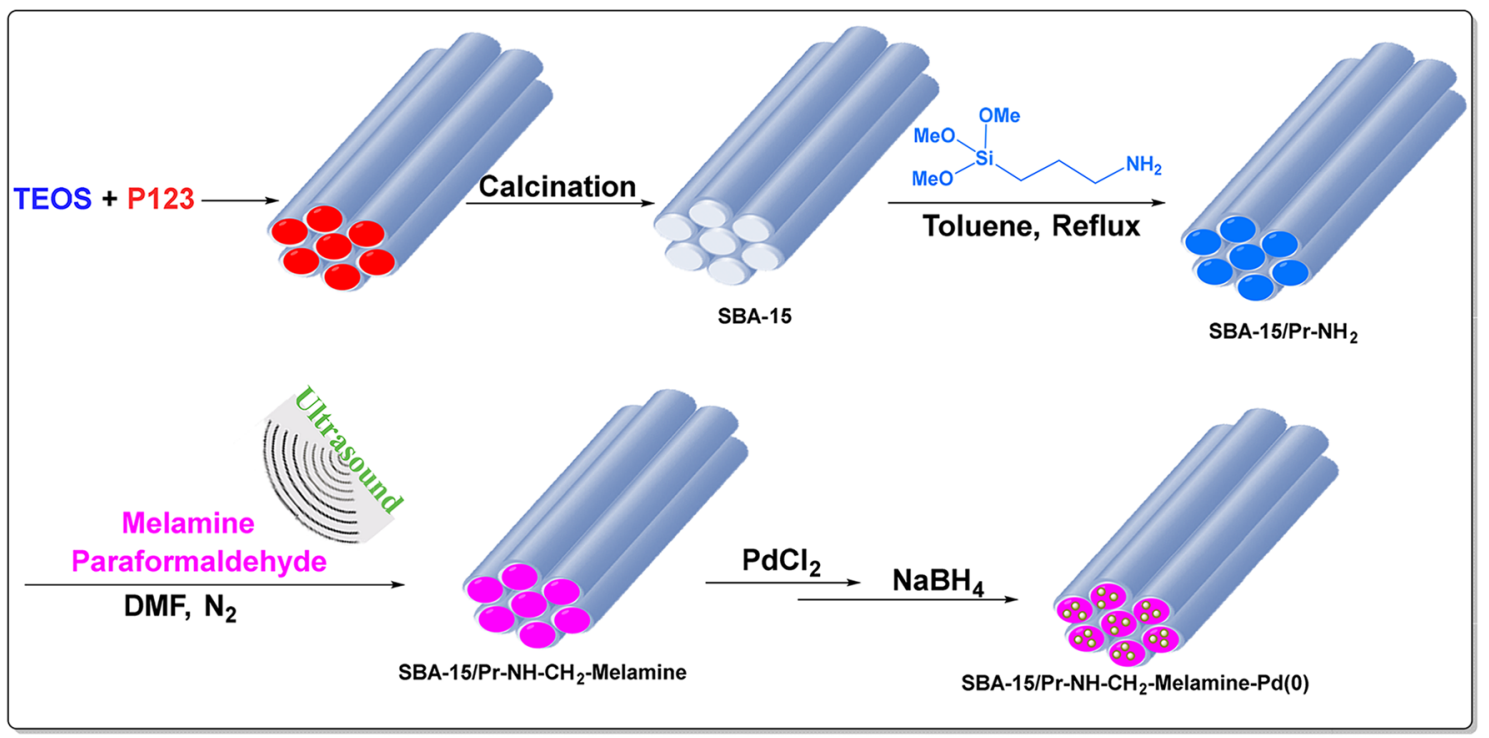

Scheme 2 Synthesis of supported SBA-15/Pr-NH-CH $2-M e l a m i n e-P d(0)$

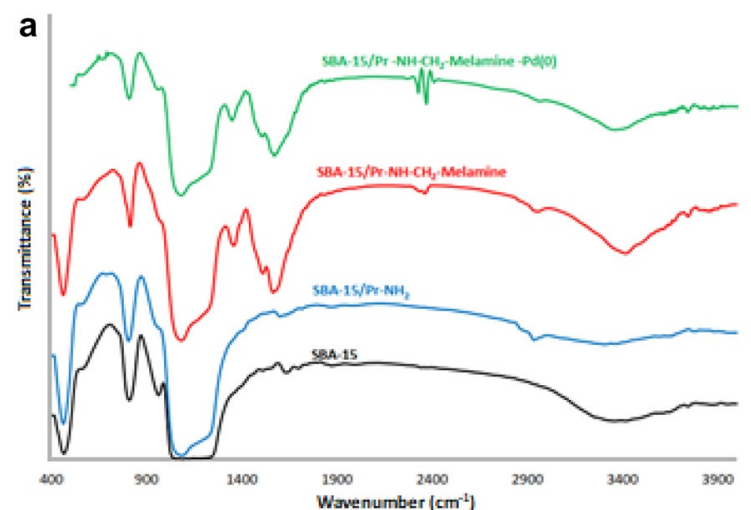

b

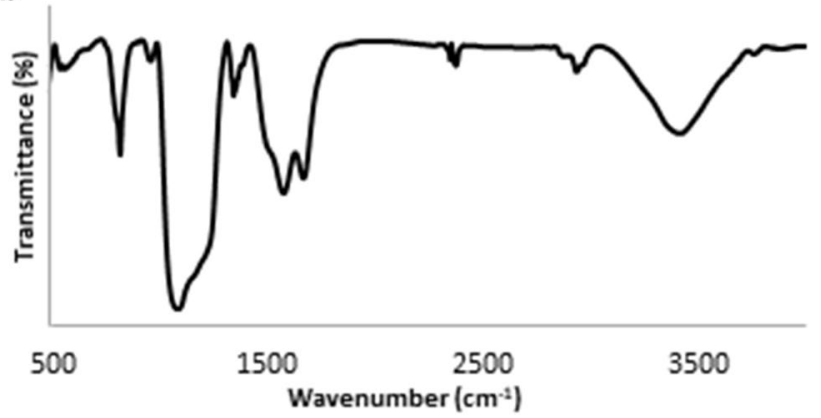

Fig. 1 FT-IR spectra for a SBA-15, SBA-15/Pr-NH $\mathrm{NH}_{2}$, SBA-15/PrNH- $\mathrm{CH}_{2}$-Melamine, fresh SBA-15/Pr -NH- $\mathrm{CH}_{2}-$ Melamine-Pd(0), b reused $\mathrm{SBA}-15 / \mathrm{Pr}-\mathrm{NH}-\mathrm{CH}_{2}-\mathrm{Melamine}-\mathrm{Pd}(0)$

To confirm the structure of the organic moieties on the surface, the solid state ${ }^{13} \mathrm{C}$-NMR analysis was performed, as illustrated in Fig. 2. The sharp peak at ca. 167 ppm can be

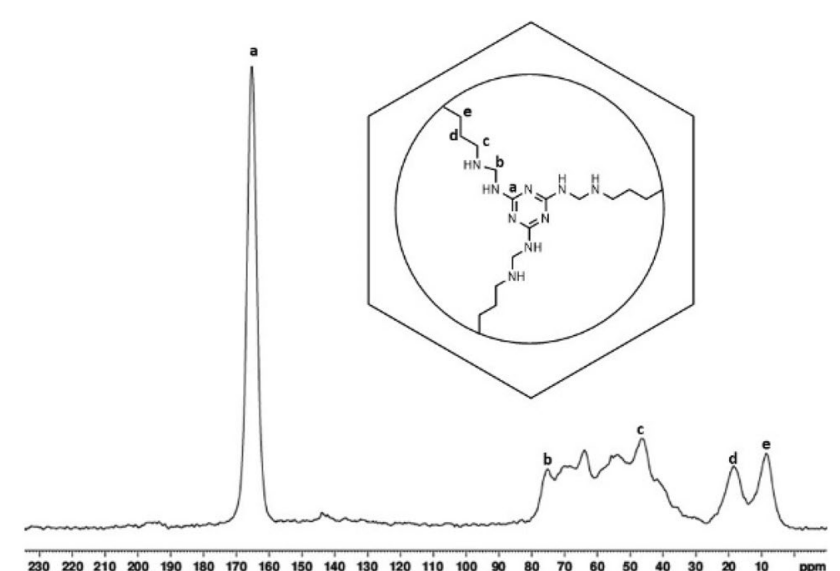

Fig. 2 Solid-state ${ }^{13} \mathrm{C}$ NMR spectrum of SBA-15/Pr-NH-CH- -Melamine-Pd(0)

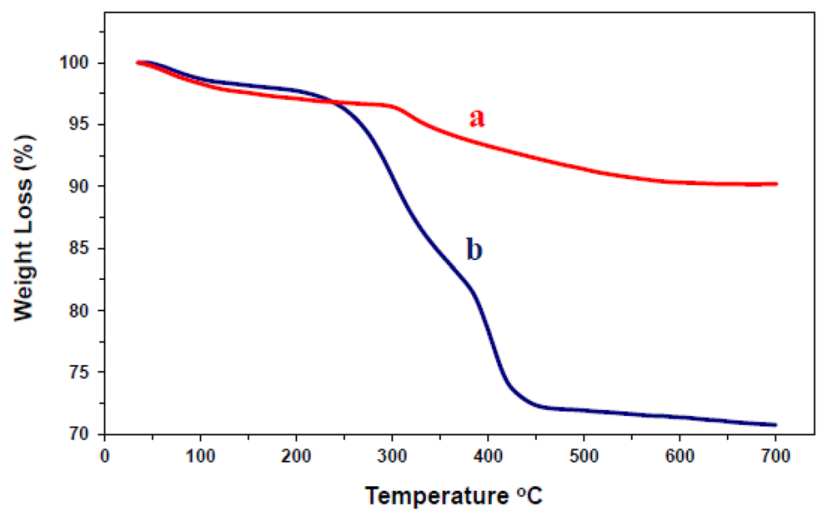

Fig. 3 a SBA-15/Pr - $\mathrm{NH}_{2}$, b SBA-15/Pr -NH- $\mathrm{CH}_{2}-$ Melamine-Pd(0) 

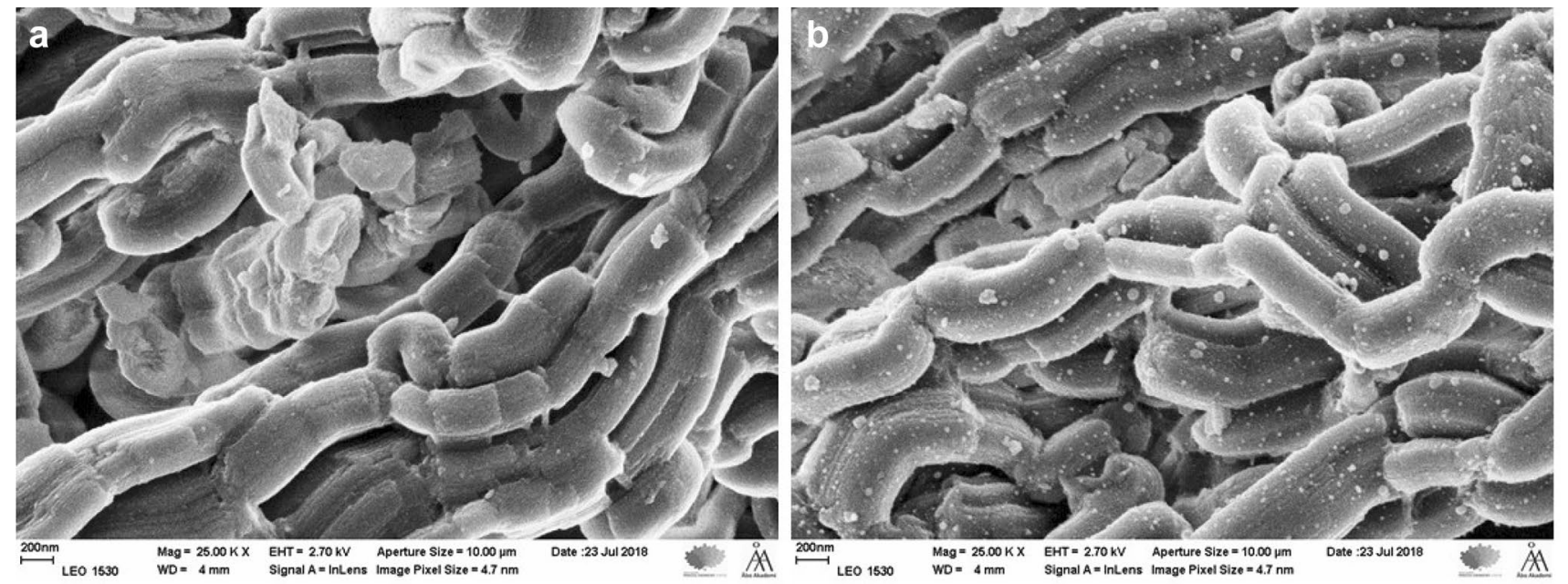

Fig. 4 SEM images of a SBA-15 and b SBA-15/Pr-NH-CH- -Melamine-Pd(0)

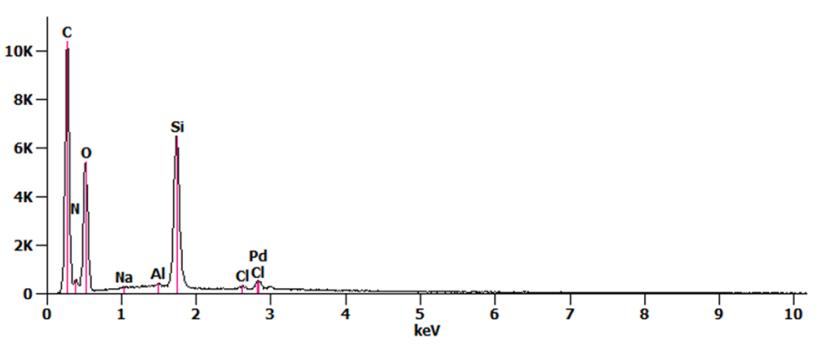

Fig. 5 EDX analysis of SBA-15/Pr-NH-CH - Melamine-Pd(0)

assigned to carbons in the aromatic chain [32]. The peak at ca. $77 \mathrm{ppm}$ is related to carbon between two nitrogen atoms (NH-C-NH) [28]. Three signals at 46.6, 18.5 and $7.5 \mathrm{ppm}$ showed presence of the propyl chain on the silicate. The non-hydrolyzed ethoxy group or unevaporated ethanol used for washing after functionalization with amino and melamine groups were also observed at ca. 15.5 (overlapping with carbon of the propyl chain) and at $59.1 \mathrm{ppm}$ [33].

In order to study thermal stability of the materials thermogravimetric analysis of SBA-15/Pr $-\mathrm{NH}_{2}$ and the final catalyst was performed (Fig. 3). Removal of physically and chemically adsorbed water molecules is associated with a mass loss of approx. 3.2\% for both samples from ambient temperature to $230^{\circ} \mathrm{C}$. In total, the SBA- $15 / \mathrm{Pr}^{-\mathrm{NH}_{2}}$ exhibited $10 \%$ weight losses, whereas the difference between the initial $3.2 \%$ and overall mass loss is approx. $6.6 \%$ and can be attributed to the propylamine loaded onto the SBA-15, with decomposition starting to happen above $310^{\circ} \mathrm{C}$. In a case of SBA-15/Pr -NH-CH$-\mathrm{CH}_{2}$-Melamine-Pd(0) sample exhibited $26.1 \%$ of weight losses, which can be attributed to the Propyl-NH- $\mathrm{CH}_{2}$-Melamine loading on the SBA-15 in addition to the initial water loss. It can be seen that the final catalyst
Table 1 The weight $\%$ and atomic $\%$ of SBA-15/Pr-NH-CH$-M e l a-$ mine-Pd(0)

\begin{tabular}{lcc}
\hline Element & Wt $(\%)$ & Atom $(\%)$ \\
\hline Carbon & 41.2 & 48.9 \\
Nitrogen & 13.6 & 13.9 \\
Oxygen & 38.0 & 33.9 \\
Silicon & 5.8 & 2.95 \\
Chlorine & 0.2 & 0.1 \\
Palladium & 1.0 & 0.1 \\
Sodium & 0.15 & 0.1 \\
Aluminum & 0.05 & 0.05 \\
\hline
\end{tabular}

is thermally stable to ca. $250^{\circ} \mathrm{C}$, well above the common reaction temperatures.

Morphology of the samples was elucidated by SEM analysis of SBA-15 and the final catalyst. Figure 4 displays the SEM images of SBA-15 and SBA-15/Pr-NH- $\mathrm{CH}_{2}-\mathrm{Mel}-$ amine-Pd(0) materials. As follows from SEM images that the fresh SBA-15 has the rod shape which did not change after functionalization and stabilization of $\operatorname{Pd}(0)$ on SBA-15, indicating stability of the supporting structure during the catalyst preparation.

A qualitative overview of the elemental composition of SBA-15/Pr-NH-CH$-\mathrm{CH}_{2}-$ Melamine-Pd(0) was evaluated by EDX at random points on the surface of the catalyst and is shown in Fig. 5. The elemental measurements confirmed the presence of all expected elements in the supported catalyst. The weight $\%$ and atomic $\%$ of the elements are shown in Table 1. They should be taken, however, with precaution since the carbon content is overestimated due to the analytical approach and a necessity to use a carbon tape to deposit the powder sample prior analysis. The real loading 


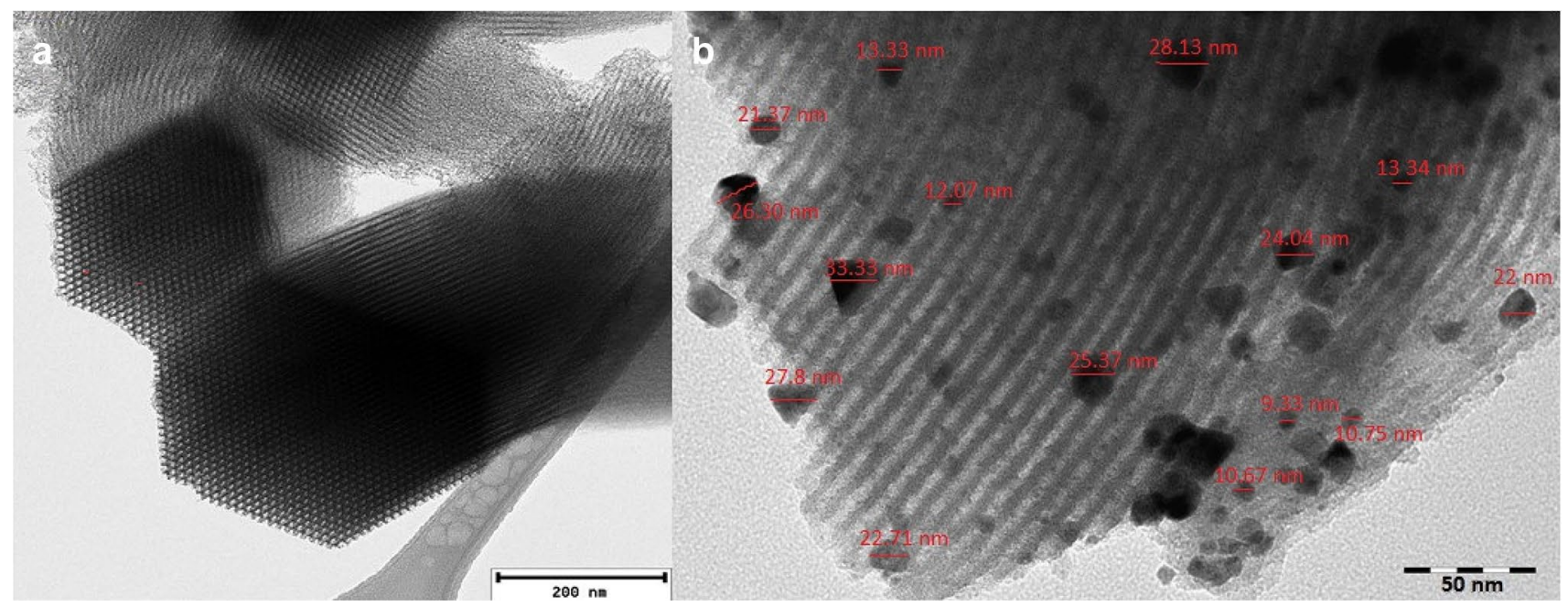

Fig. 6 TEM images of a SBA-15 and b SBA-15/Pr-NH-CH2-Melamine-Pd(0)

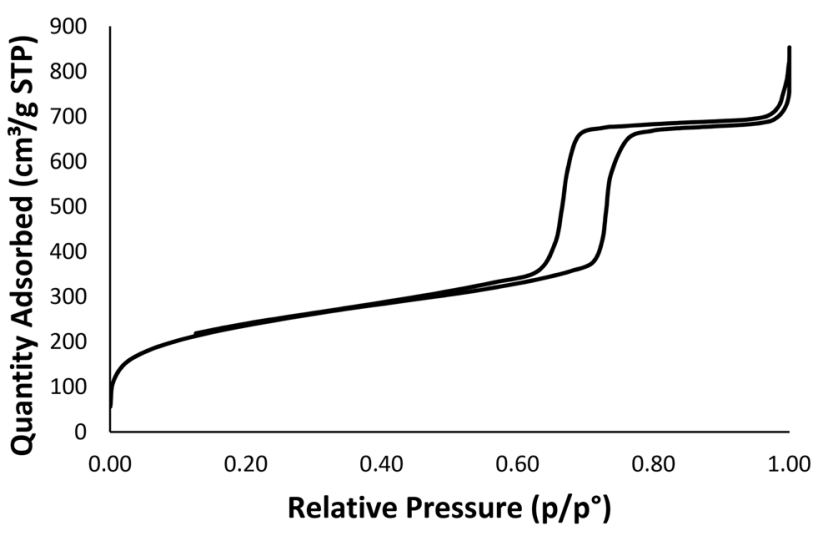

Fig. 7 Nitrogen physisorption of SBA-15

Table 2 Textural properties of the applied materials

\begin{tabular}{lll}
\hline Sample & Pore volume $\left(\mathrm{cm}^{3} \mathrm{~g}^{-1}\right)$ & $\mathrm{S}_{\mathrm{BET}}\left(\mathrm{m}^{2} \mathrm{~g}^{-1}\right)$ \\
\hline SBA-15 & 1.10 & 840 \\
Catalyst & 0.14 & 575 \\
\hline
\end{tabular}

of palladium in the catalyst was determined by ICP-OES displaying a much higher value, than obtained by EDX analysis. Nevertheless, EDX is still a valuable verification tool.

To gain more information on the structure of the catalyst and Pd size distribution TEM imaging was done. Figure 6 displays the images of SBA-15 and SBA-15/Pr-NH-CH $2^{-}$ Melamine- $\mathrm{Pd}(0)$ catalyst. Both materials exhibit uniform mesopores with a long-range order of a hexagonal array characteristic for SBA-15 materials. The dark spots in the image of SBA-15/Pr-NH-CH ${ }_{2}$-Melamin-Pd(0) with 20 to $50 \mathrm{~nm}$ diameter, can be attributed to the agglomerated $\operatorname{Pd}(0)$

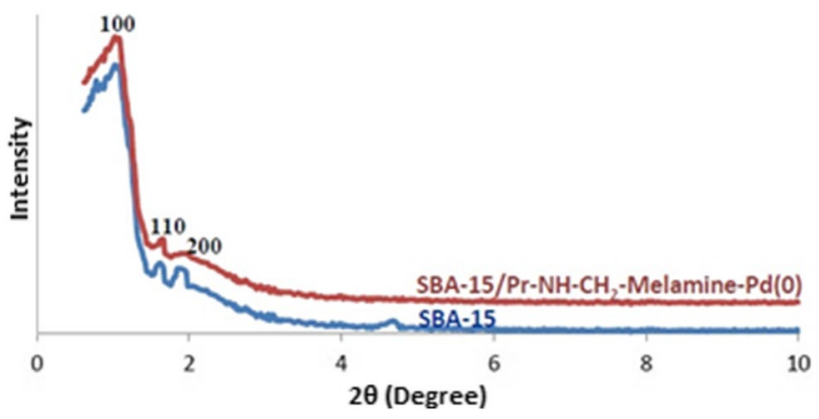

Fig. 8 Low-angle XRD patterns of the pristine SBA-15 and SBA-15/ Pr-NH-CH - -Melamine-Pd(0) catalyst

nanoparticles on the channels. After selecting random spots on the TEM image of the catalyst, the average size of the particles is found to be ca. $20 \mathrm{~nm}$.

The nitrogen adsorption-desorption isotherm (Fig. 7) was analyzed with the Brunauer-Emmett-Teller (BET) method for calculating the surface area of SBA-15. The BET surface area for the non-functionalized SBA-15 was calculated to be $840 \mathrm{~m}^{2} / \mathrm{g}$. After functionalization with organic groups and deposition of palladium nanoparticles on mesoporous silica, the surface area was diminished to $575 \mathrm{~m}^{2} / \mathrm{g}$, while the pore volume decreased from 1.10 to $0.14 \mathrm{~cm}^{3} \mathrm{~g}^{-1}$ confirming that the organic ligands and Pd nanoparticles are located in the pores of SBA-15. The Brunauer-Emmett-Teller (BET) surface areas and pore volumes of the SBA-15 and the final catalyst are summarized in Table 2.

The low-angle XRD spectra for SBA-15 and SBA-15/PrNH- $\mathrm{CH}_{2}$-Melamine-Pd(0) are shown in Fig. 8. For SBA-15, the three well-determined diffraction peaks are seen at $2 \theta$ of ca. $0.9-1.9^{\circ}$. Both synthesized materials exhibited a single strong peak (100) in XRD pattern followed by two additional 
Table 3 Optimization of conditions for the MizorokiHeck reaction

\begin{tabular}{|c|c|c|c|c|c|c|}
\hline Entry & Solvent & $\mathrm{Pd}(\mathrm{mol} \%)$ & Base & $\begin{array}{l}\text { Temperature } \\
\left({ }^{\circ} \mathrm{C}\right)\end{array}$ & Time $(\min )$ & Yield $(\%)^{\mathrm{c}}$ \\
\hline 1 & DMAC & 0.28 & $\mathrm{Et}_{3} \mathrm{~N}$ & 80 & 30 & 6.3 \\
\hline 2 & DMSO & 0.28 & $\mathrm{Et}_{3} \mathrm{~N}$ & 80 & 30 & 4.3 \\
\hline 3 & DMF & 0.28 & $\mathrm{Et}_{3} \mathrm{~N}$ & 80 & 30 & 7.9 \\
\hline 4 & NMP & 0.28 & $\mathrm{Et}_{3} \mathrm{~N}$ & 80 & 30 & 0.0 \\
\hline 5 & $\mathrm{H}_{2} \mathrm{O}$ & 0.28 & $\mathrm{Et}_{3} \mathrm{~N}$ & 80 & 30 & 0.0 \\
\hline 6 & Dioxane & 0.28 & $\mathrm{Et}_{3} \mathrm{~N}$ & 80 & 30 & 0.0 \\
\hline 7 & $\mathrm{EtOH}$ & 0.28 & $\mathrm{Et}_{3} \mathrm{~N}$ & 80 & 30 & 0.0 \\
\hline 8 & $\mathrm{CH}_{3} \mathrm{CN}$ & 0.28 & $\mathrm{Et}_{3} \mathrm{~N}$ & 80 & 30 & 2.5 \\
\hline 9 & Acetone & 0.28 & $\mathrm{Et}_{3} \mathrm{~N}$ & 80 & 30 & 1.1 \\
\hline 10 & Toluene & 0.28 & $\mathrm{Et}_{3} \mathrm{~N}$ & 80 & 30 & 0.0 \\
\hline 11 & DMF & 0.28 & $\mathrm{~K}_{2} \mathrm{CO}_{3}$ & 100 & 30 & trace \\
\hline 12 & DMF & 0.28 & $\mathrm{CsNO}_{3}$ & 100 & 30 & trace \\
\hline 13 & DMF & 0.28 & $\mathrm{Cs}_{2} \mathrm{CO}_{3}$ & 100 & 30 & trace \\
\hline 14 & DMF & 0.28 & HMTA $^{\text {b }}$ & 100 & 30 & 11.5 \\
\hline 15 & DMF & 0.28 & $\mathrm{Et}_{3} \mathrm{~N}$ & 100 & 30 & 77.5 \\
\hline 16 & DMF & 0.28 & $\mathrm{DBU}$ & 100 & 30 & trace \\
\hline 17 & DMF & 0.28 & $\mathrm{NaOAc}$ & 100 & 30 & 6.8 \\
\hline 18 & DMF & 0.28 & Free & 100 & 30 & trace \\
\hline 19 & DMF & 0.28 & $\mathrm{Et}_{3} \mathrm{~N}$ & 100 & 15 & 48.4 \\
\hline 20 & DMF & 0.56 & $\mathrm{Et}_{3} \mathrm{~N}$ & 100 & 15 & 50.6 \\
\hline 21 & DMF & 0.84 & $\mathrm{Et}_{3} \mathrm{~N}$ & 100 & 15 & 51.1 \\
\hline 22 & DMF & 1.12 & $\mathrm{Et}_{3} \mathrm{~N}$ & 100 & 15 & 52.4 \\
\hline 23 & DMF & Free & $\mathrm{Et}_{3} \mathrm{~N}$ & 100 & 15 & 0.0 \\
\hline 24 & DMF & 0.28 & $\mathrm{Et}_{3} \mathrm{~N}$ & 60 & 15 & 80 \\
\hline 25 & DMF & 0.28 & $\mathrm{Et}_{3} \mathrm{~N}$ & 80 & 15 & 85 \\
\hline 26 & DMF & 0.28 & $\mathrm{Et}_{3} \mathrm{~N}$ & 120 & 15 & '99 \\
\hline 27 & DMF & 0.28 & $\mathrm{Et}_{3} \mathrm{~N}$ & 140 & 15 & '99 \\
\hline
\end{tabular}

${ }^{a}$ Reaction conditions: iodobenzene $(1 \mathrm{mmol})$, methyl acrylate $(1.5 \mathrm{mmol})$, solvent $(1 \mathrm{ml})$, base $(1.5 \mathrm{mmol})$ and SBA-15/Pr-NH-CH- -Melamine-Pd(0) as catalyst

${ }^{\mathrm{b}}$ Hexamethylenediamine

${ }^{\mathrm{c}} \mathrm{GC}$ yield peaks $(110,200)$ which can be ascribed to a hexagonal lattice. Compared with SBA-15, the peak intensity of the final catalyst is weaker, because of a poorly ordered mesophase after functionalization of the Pr-Melamine groups inside the channels.

\subsection{Optimization of reaction conditions}

For optimizing the reaction conditions the Mizoroki-Heck reaction of iodobenzene and methyl acrylate was used as a model reaction. Variation of most important reaction parameters such as the choice of solvents, base type, the catalyst amount and reaction temperature gave the results presented in Table 3. The initial reactants ratio with an excess of methyl acrylate was adopted in order to make up for the loss of the reactant due to evaporation [34], also avoiding palladium leaching caused by the presence of unreacted iodobenzene, due to its oxidative potential [35]. In the first set of experiments performed at a relatively low reaction temperature the optimal solvent was determined (entry 1-10). Polar aprotic solvents showed to be most effective in the reaction, out of which dimethylformamide (DMF) gave the best results and $7.9 \%$ yield. In general, the polar aprotic solvents such as DMF could lead to catalyst leaching giving thereby a higher activity [36]. With the optimal solvent and at a slightly higher temperature different organic and inorganic basses were tested (entry 11-18). Low solubility of inorganic basses in DMF makes them unsuitable for systems studied in the current work, while triethylamine led to a fully homogenous reaction slurry and gave the highest yield of the coupling product (entry 15, 77.5\%) [37].

In addition to an improvement in the reaction rates utilization of triethylamine is beneficial for Pd re-precipitation [35]. In order to estimate an adequate amount of the catalyst 
capable of catalyzing the reaction within a reasonable time span, different catalyst loadings and reaction time were elucidated (entry 19-23). A minor increase in conversions was detected when the loading was increased, indicating that even small amounts of Pd are sufficient. In fact, lower loadings of Pd were claimed to be beneficial for improving the catalyst stability because the excess of Pd can lead to catalyst deactivation through Pd nanoparticles growth and agglomeration [38]. The catalyst loading of $0.28 \mathrm{~mol}$ $\%$ of palladium (entry 19, 48.4\% yield) gave satisfactory results and was further used for studying the influence of different reaction temperatures (entry 24-27). As expected, a temperature increase affected positively the reaction rate, most probably because of the aril halide activation [39]. In the current case at $120^{\circ} \mathrm{C}$ the full conversion was achieved within 15 min (entry $26,{ }^{\prime} 99 \%$ yield).

After optimizing the reaction conditions, the scope of the reaction was examined by applying the supported catalyst for the Mizoroki-Heck coupling reaction with a wide range of aryl halides $(\mathrm{Cl}, \mathrm{Br}$ and $\mathrm{I})$ and olefins. The results are listed in Table 4 containing also as a reference the melting points of obtained products and their comparison with the literature data. As can be seen from Table 4, although the palladium loading was as low as $0.28 \mathrm{~mol} \%$, excellent yields were obtained for the examined aryl iodides and bromides (entries 1 to 11). Both, activated and non-activated halides were efficiently utilized. Typically, aryl chlorides are less reactive than other halides. The same behavior was also observed in the current work under the optimal reaction conditions (entries 12 and 13). Therefore, it was concluded that the catalyst can efficiently promote the coupling reaction of aryl iodides and bromides with different olefins.

One of the most important features of heterogeneous catalysts is their recyclability. In order to estimate stability of supported SBA-15/Pr-NH- $\mathrm{CH}_{2}$-Melamine-Pd(0) for the Mizoroki-Heck reaction the performance of the recycled catalyst under optimized conditions in the reaction of iodobenzene and methyl acrylate was tested. Each reaction cycle was performed for 15 min followed by quenching the reaction by cooling to the room temperature, separating the catalyst by filtering and finally flushing several times the residue with diethyl ether and ethyl acetate. Activity of the catalyst was maintained for at least five cycles without a drop in conversion, thereafter a slight decrease was observed still showing high activity for up to the seventh cycle (Fig. 9a). Analysis of the spent catalyst after five reaction cycles also indicated the catalyst stability. FT-IR spectrum of the reused catalyst shown in Fig. 1b confirms stability of the catalyst structure exhibiting also a sharp peak at $2936 \mathrm{~cm}^{-1}$ related to solvents trapped in the catalyst.

A small decrease in conversion in the following cycle presumably can be connected with Pd leaching. More precisely, in the first cycle ca. $8 \%$ of Pd and in the second cycle ca. 5\% of Pd leached into the reaction mixture. TEM analysis of the spent catalyst after five cycles revealed presence of Pd nanoparticles and confirmed catalyst stability under the studied conditions (Fig. 9b). In addition, agglomeration of the nanoparticles was detected which potentially can be another reason for a subsequent decrease in activity. After selecting random spots on the TEM image of the reused catalyst, the average size of the particles was found to be approximately $27 \mathrm{~nm}$.

Comparison of the results in Table 5 for different reported catalysts used in the cross-coupling reaction of iodobenzene and methyl acrylate illustrates high activity of the catalyst developed in the current work. SBA-15/Pr-NH- $-\mathrm{CH}_{2}-$ Melamine- $\operatorname{Pd}(0)$ catalyst exhibited a remarkable activity with turnover frequency of $1429 \mathrm{~h}^{-1}$ which is a significant improvement compared to the already reported melamine based catalysts (entries 8-10) [45-47]. Benchmarking the current study with the literature examples can be difficult since the model reaction is often not the same. By considering analogous catalysts with melamine originating auxiliaries, such as SBA-15/CCMet/Pd(II) [48], Pd-MPMO [49], Pd/G1,2-SBA-15 [50] it can be, nevertheless, stated that in comparison with the literature reports, the current study is much more comprehensive covering the most important variables such as temperature, catalyst amounts, solvents and bases. The synthesized catalyst enabled selective processing of a vide scope of the reactants, including low reactive compounds such as non-activated bromoarenes with the use of low palladium loadings and a short reaction time, making it much more economically and environmentally desirable option.

The reaction mechanism for SBA-15/Pr-NH- $\mathrm{CH}_{2}$-Melamine- $\mathrm{Pd}(0)$ seems to follow the one recently proposed in the literature when after coordination of the olefin to the supported $\mathrm{Pd}(0)$, the base $\left(\mathrm{Et}_{3} \mathrm{~N}\right)$ attacks the alkene coordinated complex to give an alkyl $\sigma$-complex. The aryl halide then oxidizes the $\operatorname{Pd}(0)$ center, the attached base is released and the alkene coordinates to the $\mathrm{Pd}(\mathrm{II})$ complex. Subsequent hydride elimination and removal of hydrogen halide give the desired product and regenerate the catalyst to $\mathrm{Pd}(0)$ [56].

\section{Conclusions}

In summary, an efficient catalyst for the Mizoroki-Heck reaction has been developed. The catalyst comprising Pd nanoparticles deposited on melamine-grafted mesoporous SBA-15 was synthesized and characterized by FT-IR, NMR, TGA, ICP-OES, nitrogen physisorption, XRD, TEM and SEM coupled with EDX. Its performance was studied in the reaction of iodobenzene and methyl acrylate while optimizing the reaction conditions. The usability of the catalyst was demonstrated for a broad scope of the reactants, displaying 
Table 4 The Heck reaction of aryl halides with olefins catalyzed by the supported catalyst

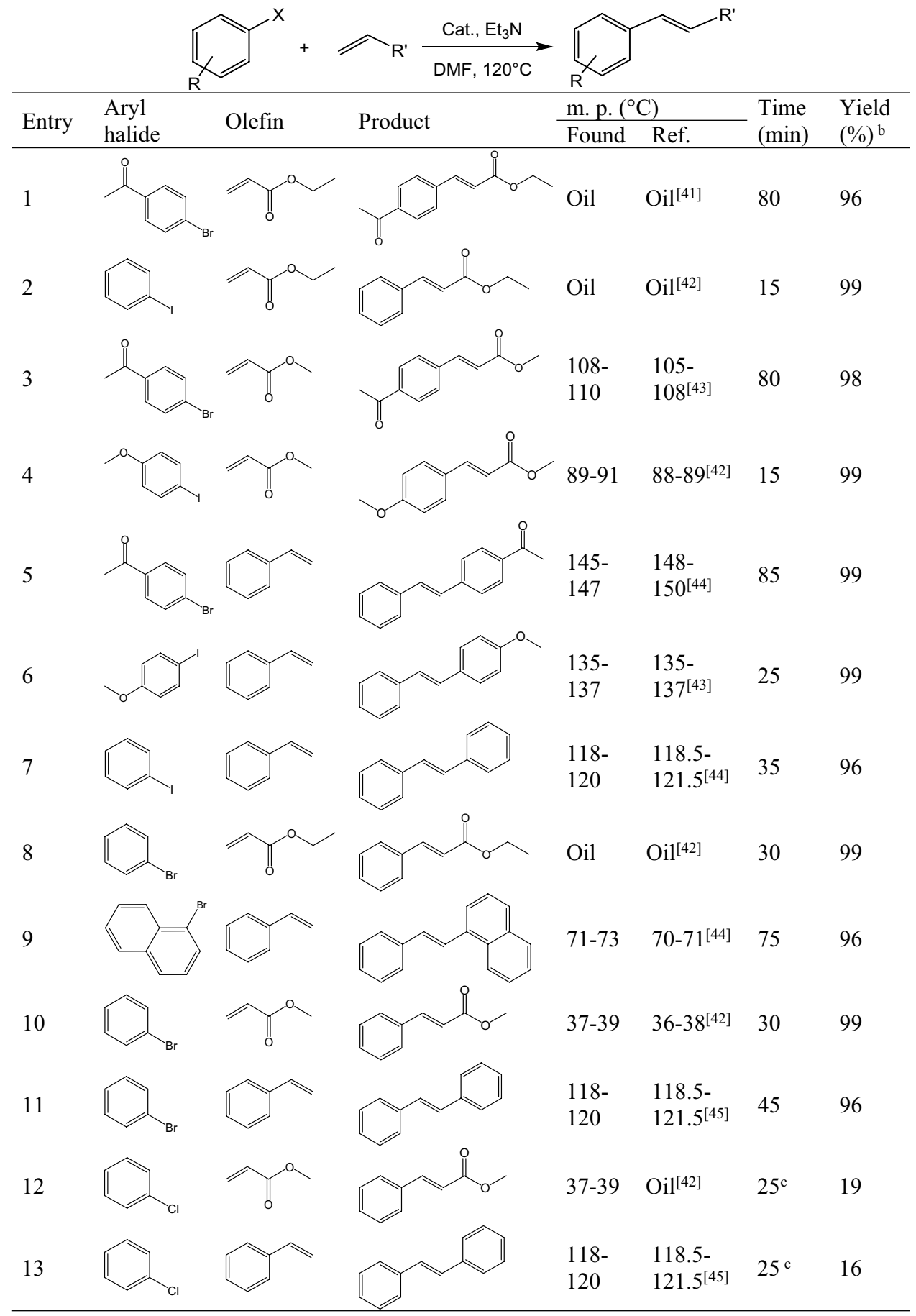

${ }^{\mathrm{a}}$ Reaction conditions: aryl halide $(1.0 \mathrm{mmol})$, olefin $(1.5 \mathrm{mmol})$, solvent $(1 \mathrm{~mL})$ and base $(1.5 \mathrm{mmol})$, $0.28 \mathrm{~mol} \% \mathrm{Pd}$, reaction temperature $120^{\circ} \mathrm{C}$

${ }^{\mathrm{b}} \mathrm{GC}$ yield

${ }^{\mathrm{c}}$ Time (h) 

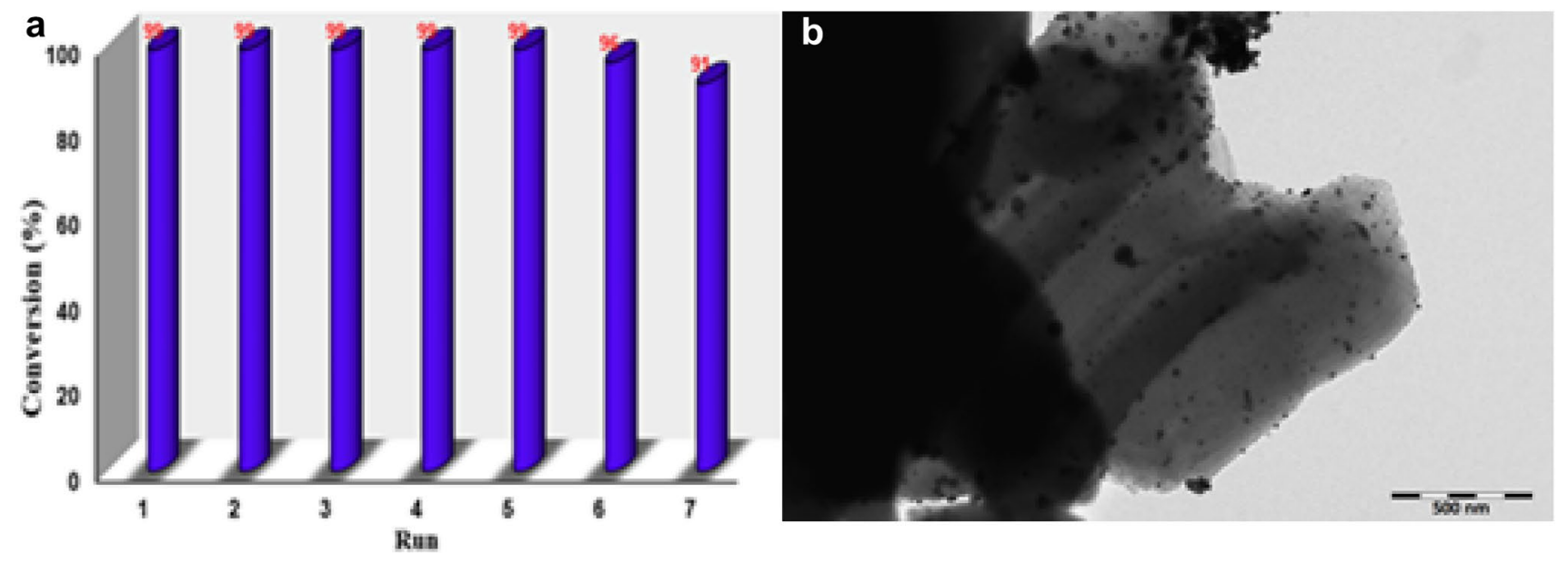

Fig. 9 a Catalyst reusability study in the reaction of iodobenzene and methyl acrylate under the optimal conditions. b TEM image of the spent catalyst used in five reaction cycles

Table 5 Comparison of activity of different catalysts in the cross-coupling reactions of iodobenzene with methyl acrylate

\begin{tabular}{|c|c|c|c|c|c|}
\hline Entry & Catalyst & Time (h) & $\mathrm{T}\left({ }^{\circ} \mathrm{C}\right)$ & Yield (\%) & TOF $\left(h^{-1}\right)^{b}$ \\
\hline 1 & $\mathrm{Pd} / \mathrm{C}[34]$ & 0.5 & 140 & 100 & 714 \\
\hline 2 & $\mathrm{Pd}(\mathrm{OAc})_{2}$ (ligand free) [51] & 1.5 & 80 & 91 & 60 \\
\hline 3 & Palladacycle [52] & 0.3 & 140 & 100 & 602 \\
\hline 4 & $\mathrm{Pd} / \mathrm{C}$ particles $[53]$ & 24 & 100 & 37 & 0.3 \\
\hline 5 & Pd(nano)/MNP@IL-SiO 2 [54] & 24 & 110 & 99 & 12 \\
\hline 6 & Pd-DABCO- $\gamma-\mathrm{Fe}_{2} \mathrm{O}_{3}[55]$ & 0.5 & 100 & 90 & 180 \\
\hline 7 & MNP@SiO2 @NHC-Pd(II) [56] & 2 & 120 & 99 & 198 \\
\hline 8 & Pd@MFR1 [47] & 3 & 110 & 92 & 13 \\
\hline 9 & MNPs-Mel-Pd [45] & 8 & 100 & 96 & 3 \\
\hline 10 & MNPs-Mel-Pd [46] & 0.5 & 100 & 98 & 158 \\
\hline 11 & SBA-15/Pr-NH-CH - -Melamin-Pd( $(0)^{\mathrm{a}}$ & 0.25 & 120 & >99 & 1429 \\
\hline
\end{tabular}

${ }^{a}$ This study

${ }^{\mathrm{b}} \mathrm{TOF}=$ moles of reactant converted/(moles of palladium $\mathrm{x}$ time $\left.(\mathrm{h})\right)$

its efficiency in coupling iodo- and bromo-aromatics with different olefins, while its high activity enabled application of small amounts of Pd and short reaction times. The material was possible to re-use for at least seven consecutive cycles preserving its high activity.

Funding Open access funding provided by Abo Akademi University $(\mathrm{ABO})$.

Open Access This article is licensed under a Creative Commons Attribution 4.0 International License, which permits use, sharing, adaptation, distribution and reproduction in any medium or format, as long as you give appropriate credit to the original author(s) and the source, provide a link to the Creative Commons licence, and indicate if changes were made. The images or other third party material in this article are included in the article's Creative Commons licence, unless indicated otherwise in a credit line to the material. If material is not included in the article's Creative Commons licence and your intended use is not permitted by statutory regulation or exceeds the permitted use, you will need to obtain permission directly from the copyright holder. To view a copy of this licence, visit http://creativecommons.org/licenses/by/4.0/.

\section{References}

1. Chuentragool P, Yadagiri D, Morita T, Sarkar S, Parasram M, Wang Y, Gevorgyan V (2019) Angew Chem Int Ed 58:1794-1798

2. Sweeney JB, Adams K, Crook R, Doulcet J, Thapa B, Tran F (2018) J Catal 360:97-101

3. Motevalizadeh SF, Alipour M, Ashori F, Samzadeh-Kermani A, Hamadi H, Ganjali MR, Aghahosseini H, Ramazani A, Khoobi M, Gholibegloo E (2018) Appl Organomet Chem 32:e4123

4. Li Y, Wang K, Ping Y, Wang Y, Kong W (2018) Org Lett 20:921-924

5. Yu J, Hong Z, Yang X, Jiang Y, Jiang Z, Su W (2018) Beilstein J Org Chem 14:786-795

6. Koy M, Sandfort F, Tlahuext-Aca A, Quach L, Daniliuc CG, Glorius $\mathrm{F}$ (2018) Chem - A Eur J 24:4552-4555 
7. Bangar PG, Jawalkar PR, Dumbre SR, Patil DJ, Iyer S (2017) Appl Organomet Chem 32:1-6

8. Shi KJ, Shu CH, Wang CX, Wu XY, Tian H, Liu PN (2017) Org Lett 19:2801-2804

9. Kurandina D, Parasram M, Gevorgyan V (2017) Angew Chem Int Ed 56:14212-14216

10. Wang C, Xiao G, Guo T, Ding Y, Wu X, Loh TP (2018) J Am Chem Soc 140:9332-9336

11. Liwosz TW, Chemler SR (2012) J Am Chem Soc 134:2020-2023

12. Nuri A, Vucetic N, Smått JH, Mansoori Y, Mikkola JP, Murzin DY (2019) Catal Lett 149:1941-1951

13. Nuri A, Vucetic N, Smått JH, Mansoori Y, Mikkola JP, Murzin DY (2020) Catal Lett 150:2617-2629

14. Ananikov VP, Orlov NV, Beletskaya IP (2007) Organometallics 26:740-750

15. Jaska CA, Manners I (2004) J Am Chem Soc 126:9776-9785

16. Huang Y, Ma T, Huang P, Wu D, Lin Z, Cao R (2013) ChemCatChem 5:1877-1883

17. Zhang Q, Mao Z, Wang K, Thanh N, Phan S, Zhang F (2020) Green Chem 22:3239-3247

18. Wang K, Liu J, Zhang F, Zhang Q, Jiang H, Tong M, Xiao Y, Thanh N, Phan S, Zhang F, Appl ACS (2019) Mater Interfaces 11:41238-41244

19. Khajehzadeh M, Moghadam M (2018) J Organomet Chem 863:60-69

20. Zhang Q, Zhao X, Wei H-X, Li J-H, Luo J (2017) Appl Organomet Chem 31:1-9

21. Amarasekara AS, Owereh OS (2010) Catal Commun 11:1072-1075

22. Zhu Y, Kaskel S, Ikoma T, Hanagata N (2009) Microporous Mesoporous Mater 123:107-112

23. Zhao W, Chen H, Li Y, Li L, Lang M, Shi J (2008) Adv Funct Mater 18:2780-2788

24. Zhu S, Zhou Z, Zhang D, Jin C, Li Z (2007) Microporous Mesoporous Mater 106:56-61

25. Lazar A, Vinod CP, Singh AP (2016) New J Chem 40:2423-2432

26. Zhao D, Huo Q, Feng J, Chmelka BF, Stucky GD (1998) J Am Chem Soc 120:6024-6036

27. Srivastava R, Srinivas D, Ratnasamy P (2006) Microporous Mesoporous Mater 90:314-326

28. Al Hamouz OCS, Adelabu IO, Saleh TA (2017) J Environ Manag 192:163-170

29. Jiang Y, Gao Q (2006) J Am Chem Soc 128:716-717

30. Desforges A, Backov R, Deleuze H, Mondain-Molval O (2005) Adv Funct Mater 15:1689-1695

31. Shahbazi A, Younesi H, Badiei A (2011) Chem Eng J 168:505-518
32. Jürgens B, Irran E, Senker J, Kroll P, Müller H, Schnick W (2003) J Am Chem Soc 125:10288-10300

33. Kim SY, Parambadath S, Park SS, Ha CS (2017) J Nanosci Nanotechnol 17:7565-7574

34. Liang L, Nie L, Jiang M, Bie F, Shao L, Qi C, Zhang XM, Liu X (2018) New J Chem 42:11023-11030

35. Zhao F, Bhanage BM, Shirai M, Arai M (2000) Chem A Eur J 6:843-848

36. Caporusso AM, Innocenti P, Aronica LA, Vitulli G, Gallina R, Biffis A, Zecca M, Corain B (2005) J Catal 234:1-13

37. Liu G, Hou M, Song J, Jiang T, Fan H, Zhang Z, Han B (2010) Green Chem 12:65-69

38. de Vries AHM, Mulders JMCA, Mommers JHM, Henderickx HJW, de Vries JG (2003) Org Lett 5:3285-3288

39. Kamilah S, Soh C, Jusoh SA, Sukeri M, Yusof M, Khairul WM, Shamsuddin M (2018) Int J Eng Technol 7:467-469

40. Huang S-H, Chen J-R, Tsai F-Y (2010) Molecules 15:315-330

41. Sun P, Zhu Y, Yang H, Yan H, Lu L, Zhang X, Mao J (2012) Org Biomol Chem 10:4512-4515

42. Schmidt B, Berger R (2013) Adv Synth Catal 355:463-476

43. Yu L, Huang Y, Wei Z, Ding Y, Su C, Xu Q (2015) J Org Chem 80:8677-8683

44. Górski B, Talko A, Basak T, Barbasiewicz M (2017) Org Lett 19:1756-1759

45. Bodaghifard MA (2019) J Organomet Chem 886:57-64

46. Aryanasab F, Shabanian M, Laoutid F, Vahabi H (2021) Appl Organomet Chem 2:1-12

47. Zhong S (2017) Turk J Chem 41:773-783

48. Veisi H, Kordestani D, Faraji AR (2014) J Porous Mater 21:141-148

49. Elavarasan S, Kala K, Muhammad I, Bhaumik A, Sasidharan M (2019) Mol Catal 476:1-10

50. Lou Y, Shantz DF (2017) J Mater Chem A 5:14070-14078

51. Han W, Liu N, Liu C, Jin ZL (2010) Chin Chem Lett 21:1411-1414

52. Rosol M, Moyano A (2005) J Organomet Chem 690:2291-2296

53. Cassez A, Kania N, Hapiot F, Fourmentin S, Monflier E, Ponchel A (2008) Catal Commun 9:1346-1351

54. Omar S, Abu-Reziq R (2014) J Phys Chem C 118:30045-30056

55. Sobhani S, Pakdin-Parizi Z (2014) Appl Catal A Gen 479:112-120

56. Nuri A, Mansoori Y, Bezaatpour A (2019) Appl Organomet Chem $33: 1-15$

Publisher's Note Springer Nature remains neutral with regard to jurisdictional claims in published maps and institutional affiliations. 